Check for updates

Sheffield

Cite this as: BMJ 2020;370:m3655 http://dx.doi.org/10.1136/bmj.m3655 Published: 17 September 2020

\title{
A\&Es get funding boost as NHS 111 trials booking patients for urgent care
}

Emma Wilkinson

Funding has been made available to upgrade 25 hospital accident and emergency departments in England ahead of winter, the government has announced.

Bedfordshire, York, Liverpool, and Bristol are among the trusts that will receive a share of the £15om capital injection to expand their A\&E departments to make more physical space to treat patients and manage patient flow while improving infection control.

England's health and social care secretary, Matt Hancock, also announced details of a pilot scheme for NHS 111 to be the "first point of contact" for patients seeking urgent care.

Under the plans, which are intended to roll out nationally from December, patients will call the helpline before being booked into A\&E or urgent treatment centres, or to see a GP.

Pilots are already under way in Cornwall, Portsmouth and South-east Hampshire, and Blackpool and have just begun in Warrington, said the Department of Health and Social Care.

Hancock said the extra funding for 25 A\&E departments was in addition to £30om already announced for 117 trusts to upgrade their facilities. "We are investing $£ 450 \mathrm{~m}$ to make sure our A\&E departments are ready for winter. Hospitals around the country will be able to expand and upgrade to ensure they can continue safely treating patients in the coming months," he said. The NHS 111 pilots would build on work already done in the peak of the covid-19 pandemic and would test the delivery of quicker access to care while ensuring that NHS staff weren't overwhelmed, Hancock added.

Cliff Mann, the NHS national clinical director for urgent and emergency care, said, "This additional investment will help us continue the development of NHS 111 and provide a broader range of services, with direct booking that will ensure all patients can see the right clinicians in the right setting, and address the extra challenges posed by covid-19 so that emergency departments can safely treat those patients who do require their services."

Katherine Henderson, president of the Royal College of Emergency Medicine, said, “A further boost to capital funding to help redevelop our most challenged emergency departments is very welcome and vital to help ensure social distancing and reduce the spread of infection."

NHS Providers welcomed news of the investment, given that the NHS was likely to be "under significant pressure" this winter, it said, but added that the announcement had been expected in June.
Its chief executive, Chris Hopson, said that the proposals to use NHS 111 as a "front door" to emergency care and to redirect patients to the right service was the right approach. "They have been developed after extensive work between national and local leaders. It is appropriate that they should be properly piloted before they are fully rolled out, but we are hopeful these pilots will prove successful."

Donal O’Donoghue, Royal College of Physicians registrar, warned that messages to the public about any changes in accessing urgent care needed to be clear and should not deter people from seeking help when they need it. "Any steps the government can take to prevent this are certainly welcome, particularly given the added pressures and risks of covid-19. But for these changes to be successful we need to make sure that the patient experience is better than before, including ensuring that waiting times are reduced," he said. 